\title{
Cost effectiveness of chemohormonal therapy in patients with metastatic hormone-sensitive and non-metastatic high-risk prostate cancer
}

\author{
Custo-efetividade da adição de quimioterapia ao tratamento hormonal do \\ câncer de próstata metastático sensível a hormônio ou localizado de alto risco
}

\author{
Pedro Nazareth Aguiar Jr. ${ }^{1}$, Carmélia Maria Noia Barreto², Bárbara de Souza Gutierres ${ }^{3}$, \\ Hakaru Tadokoro ${ }^{4}$, Gilberto de Lima Lopes Jr. ${ }^{5}$
}

\begin{abstract}
Objective: To assess the cost-effectiveness of chemohormonal therapy in patients with metastatic hormone-sensitive and nonmetastatic high-risk prostate cancer. Methods: An analytical decision model was developed to determine the cost-effectiveness of chemohormonal therapy versus androgen deprivation therapy alone in patients with metastatic hormone-sensitive prostate cancer and patients with non-metastatic high-risk prostate cancer. The costeffectiveness in metastatic patients with a high-volume disease was assessed separately. The model used data from randomized clinical trials and drug acquisition costs in Brazil. In addition, the costs of post-progression therapies have been included in this model. The benefits to health are expressed as the quality-adjusted life-years, and the incremental cost-effectiveness ratios were calculated. Results: Chemohormonal therapy may be associated with improved qualityadjusted life-years for all patient. The improvement was more than six times greater for patients with high-volume metastatic disease. In these patients, the incremental cost-effectiveness ratios were up to $74 \%$ lower than the incremental cost-effectiveness ratios of patients with non-metastatic disease. Conclusion: Chemohormonal therapy has been more cost-effective in patients with high-volume metastatic disease.
\end{abstract}

Keywords: Economics, pharmaceutical; Prostatic neoplasms/drug therapy; Cost control; Public health

\section{RESUMO}

Objetivo: Avaliar a relação custo-efetividade da adição de quimioterapia hormonal em pacientes com câncer de próstata metastático sensível a hormônio ou localizado de alto risco. Métodos: Um modelo de decisão analítico foi desenvolvido para determinar o custo-efetividade da adição de quimioterapia versus a monoterapia de privação de andrógeno para pacientes com câncer de próstata metastático hormônio-sensível e pacientes de alto risco com câncer de próstata não metastático. 0 custo-efetividade em pacientes metastáticos com um alto volume da doença foi verificado isoladamente. Os dados do modelo foram obtidos de ensaios clínicos randomizados utilizando custos de aquisição de medicamentos no Brasil. Os custos de terapias pós-progressão também foram incluídos no modelo. Os efeitos foram expressos em anos de vida ajustados por qualidade, e foram calculadas as razões de custo-efetividade incremental. Resultados: A adição de quimioterapia levou a um ganho de anos de vida ajustados por qualidade para todos os doentes. Este incremento foi seis vezes maior para os pacientes com doença metastática de alto volume. Nestes pacientes, as taxas do custo incremental por anos de vida ajustados por qualidade foram até $74 \%$ mais baixos do que 0 aumento das taxas dos pacientes com doença não metastática. Conclusão: A adição de quimioterapia foi mais custo-efetiva para pacientes com doença metastática de alto volume.

Descritores: Farmacoeconomia; Neoplasias da próstata/tratamento farmacológico; Controle de custos; Saúde pública

\footnotetext{
'Faculdade de Medicina do ABC, Santo André, SP, Brazil.

${ }^{2}$ Beneficência Portuguesa de São Paulo, São Paulo, SP, Brazil.

${ }^{3}$ Universidade Paulista, São Paulo, SP, Brazil.

${ }^{4}$ Universidade Federal de São Paulo, São Paulo, SP, Brazil.

${ }^{5}$ Sylvester Comprehensive Cancer Center, Miami University, USA

Corresponding author: Pedro Nazareth Aguiar Jr. - Rua Correia Dias, 171 - Paraíso - Zip code: $04104-000$ - São Paulo, SP, Brazil - Phone: (55 11) 3371-5700 - E-mail: pnajpg@hotmail.com

Received on: Feb 6, 2017-Accepted on: May 4, 2017

Conflict of interest: none.

DOI: 10.1590/S1679-45082017GS4017
} 


\section{INTRODUCTION}

Prostate cancer is the second most common neoplasm in men worldwide with an estimated 1,100,000 new cases and 307,000 deaths reported in 2012. ${ }^{(1)}$ In Brazil, between 2016 and 2017, the Instituto Nacional de Cancer José Alencar Gomes da Silva (INCA) estimates that prostate cancer will be the most common neoplasm among men, excluding non-melanoma skin cancers. ${ }^{(2)}$

U.S. data indicate that of all prostate cancer cases, $80 \%$ are confined to the prostate gland, $12 \%$ are locally advanced and invaded regional lymph nodes, and $4 \%$ are distant metastases; approximately $4 \%$ of the cases have an unknown stage. ${ }^{(3)}$ Although the lack of data in Brazil, it is hypothesized that there will be a greater proportion of metastatic disease reported at diagnosis due to socioeconomic reasons. ${ }^{(4)}$

The main treatment for metastatic disease has been androgen deprivation therapy (ADT) since mid-1966, when Charles B. Huggins was awarded with the Nobel Prize. He showed that androgen deprivation was an effective treatment in patients with locally advanced or metastatic prostate cancer, with a $15 \%$ decrease in the cancer-specific mortality rate. ${ }^{(5)}$ However, there was no change in the overall survival (OS) of patients with localized disease. ${ }^{(5)}$

Recent studies have reviewed this treatment paradigm and have compared ADT alone versus ADT in combination with chemotherapy for patients with localized, advanced, or metastatic disease. The GETUG-AFU 15 study (Androgen-deprivation therapy alone or with docetaxel in non-castrate metastatic prostate cancer) did not show any improvement in OS following treatment with ADT plus docetaxel versus ADT alone; however, an objective response rate of $28 \%$ was achieved in patients who were treated with a combination of ADT and docetaxel. ${ }^{(6)}$ The median progression free survival (PFS) for the ADT plus docetaxel group increased to 23.4 months from 18.5 months for the ADT group (hazard ratio - HR: $0.75,95 \%$ of confidence interval - 95\% CI: 0.59-0.94; $\mathrm{p}=0.015){ }^{(6)}$

In addition, the Systemic Therapy in Advancing or Metastatic Prostate Cancer: Evaluation of Drug Efficacy (STAMPEDE) and GETUG-AFU 12 studies have assessed chemotherapy plus ADT for non-metastatic patients with a high-risk of localized disease (e.g. elevated prostate specific antigen - PSA at diagnosis and highgrade tumors). In the STAMPEDE study, $24 \%$ of the patients did not present with metastatic disease and the results of the study pointed to a benefit in terms of OS and PFS in favor of the combined treatment. ${ }^{(7)}$ In the GETUG-AFU 12 study, which only included patients with non-metastatic disease, there was an increase in the recurrence free survival (RFS) in patients that received the combination treatment of chemotherapy plus ADT compared to patients that were treated with ADT alone (HR: $0.71 ; \mathrm{p}=0.017){ }^{(8)}$

Pharmacoeconomics evaluates the costs and benefits of drug therapy under the following aspects: the cost of this treatment to the health system, how much it improves disease prognoses, the demand and supply of the treatment for a given disease, and the budget. ${ }^{(9)}$ The main objective of pharmacoeconomics is to equate the increasing financial demand of new treatments with sustainability, so that the treatment for a specific subset of the population is available for everyone who will benefit the most. ${ }^{(9)}$ There are two important concepts to consider: the quality-adjusted life-year (QALY) and incremental cost-effectiveness ratio (ICER). ${ }^{(10)}$

Quality-adjusted life-year measures both the number of years gained by taking a treatment and the quality of life during the treatment period. This is measured in terms of the patient's ability to carry out daily activities. This is the life-years provided by the treatment adjusted to the quality of life score (also known as utility, on a scale of zero, dead, to 1 , full capacity). ${ }^{(10)}$

Incremental cost-effectiveness ratio evaluates the cost-effectiveness of the treatment intervention, i.e., the cost for each QALY gained by the treatment. The value is the ratio between the difference in treatment costs and the QALY gained. ${ }^{(10)}$

\section{OBJECTIVE}

To evaluate the cost-effectiveness of adding chemotherapy to androgen deprivation therapy in three distinct subgroups of patients with prostate cancer: patients with metastatic disease, patients with extensive metastatic disease and patients with high-risk non-metastatic disease.

\section{METHODS}

We developed an analytical model to determine the cost-effectiveness of adding chemotherapy to ADT versus $\mathrm{ADT}$ alone for the initial treatment of prostate cancer. In our model, we compared early chemotherapy plus ADT or ADT alone. The model was developed in the Microsoft Excel Professional Plus 2013.

The type of treatment after progression and death (Figure 1) were also included. The same model was applied to patients with hormone-sensitive metastatic disease and high-risk non-metastatic disease. Subsequently, 


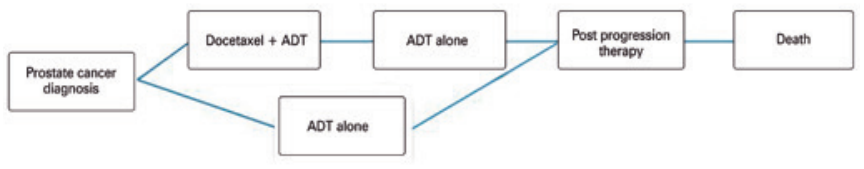

ADT: androgen deprivation therapy.

Figure 1. Type of treatment after progression and death

analyses were performed considering only the metastatic patients with a high-volume of disease according to the definitions of the CHAARTED study (ChemoHormonal therapy versus androgen ablation randomized trial for extensive disease in prostate câncer): presence of visceral metastasis and/or four or more lesions in the bone with at least one lesion affecting a bone outside of the vertebrae or pelvis. ${ }^{(11)}$

To calculate the QALY of each treatment, the different health states present in the model received a utility score based on the literature. ${ }^{(12)}$ The utility score for chemotherapy was obtained from quality of life analyzes previously published.(8,11) Utility values were reduced according to the adverse events caused by each first-line treatment using the disutility scores available in the literature. ${ }^{(13-15)}$

The costs for each treatment and the costs of the post-progression therapies were considered. These costs were based on the Brazilian discount price index accessed in June 2016. ${ }^{(16)}$ All costs were converted to US dollars based on an exchange rate of $\mathrm{R} \$ 3,25$ to US\$ 1.00. The costs of adverse events were not considered in the Brazilian model because there has not been enough data published in the local literature to extrapolate the costs from other countries (such as the United States or the United Kingdom), which may not accurately represent the reality in Brazil. All costs included in the analysis are summarized in the table 1.

Table 1. Costs summary

\begin{tabular}{lcc}
\hline Costs & Docetaxel + ADT (\$) & ADT alone (\$) \\
\hline Docetaxel & $4,733.90$ & 0 \\
ADT & $5,441.74$ & $3,886.95$ \\
Post progression & $9,618.64$ & $9,863.14$ \\
Adverse events & NA & NA \\
Supportive care & NA & NA \\
Total & $19,794.28$ & $13,750.09$ \\
\hline
\end{tabular}

NA: not assessed; ADT: androgen deprivation therapy.

Data regarding PFS, or RFS in the case of nonmetastatic patients, and OS were extracted from randomized clinical trials. ${ }^{(8,11)}$ A lifetime mortality estimate was not made since the follow-up time for each study was adequate to demonstrate the difference in outcomes between each type of treatment ( 8.8 years in the GETUG-AFU 12 study and 28.9 months in the CHAARTED study). ${ }^{(8,11)}$ The effects were expressed in QALY and ICER.

After analyzing the clinical scenario of each group of patients a probabilistic sensitivity analysis was performed, taking into account the CI of RFS, PFS and OS. In addition, scenarios with $100 \%$ increase or $50 \%$ discount on the cost of docetaxel cost and QALY gain were considered. These analyses were performed to confirm the robustness of the data and facilitate the comparison of the results between the different patient subgroups. The probabilistic sensitivity analysis results are presented in a Tornado diagram.

\section{RESULTS}

\section{High-risk non-metastatic disease}

In the analysis of patients with high-risk non-metastatic disease, the addition of docetaxel to ADT promoted a gain of 0.12 QALY. As a result, the incremental cost of this therapy was US\$25,929.62 per QALY. In the probabilistic sensitivity analysis, $53 \%$ of the scenarios evaluated were cost-effective based on the three-fold gross domestic product (GDP) per capita (US\$ 33,000.00) per QALY. In 33\% of the scenarios evaluated ADT alone was cost-effective (Figure 2).

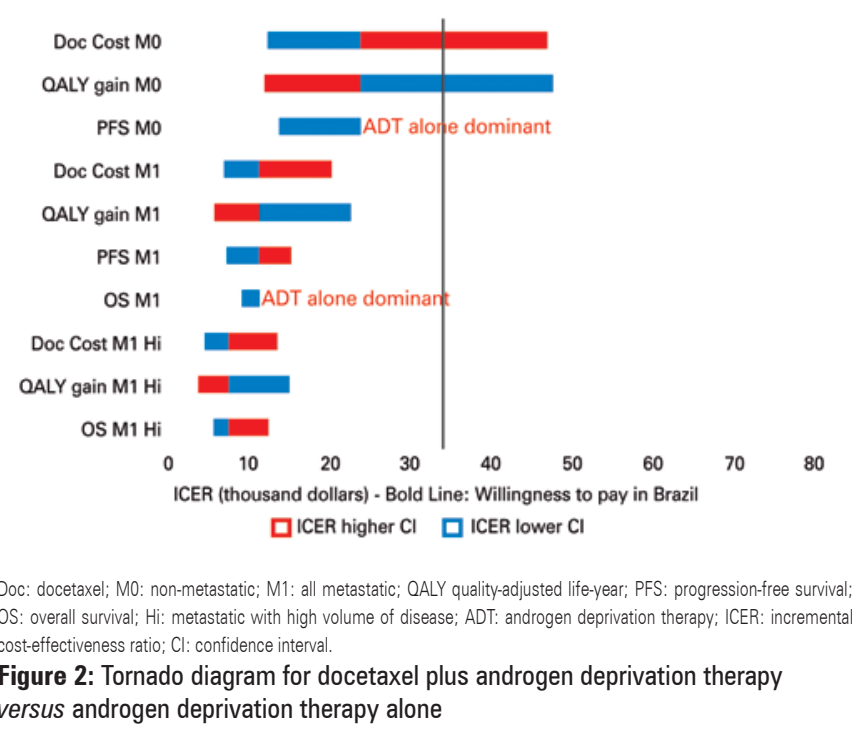

\section{Metastatic disease}

In the metastatic disease analysis, there was an increase of 0.53 QALY with the addition of docetaxel to ADT. The incremental cost per patient was $\mathrm{R} \$ 11.228 .55$ per 
QALY. Almost all of the scenarios evaluated in the probabilistic sensitivity analysis were considered costeffective ( $80 \%$ of the cases). In the remaining (20\%) scenarios, ADT alone was cost effective (Figure 2).

\section{High-volume metastatic disease}

Considering only patients with a high-volume of metastatic disease, there was an increase of 0.70 QALY with the addition of docetaxel to ADT. The incremental cost in this subpopulation was US\$ 8,416.93 per QALY. The majority of scenarios evaluated in the PSA were within the cost-effectiveness threshold (73\%). In this subgroup, ADT alone was not considered to be costeffective (Figure 2).

Figure 3 presents all of the scenarios considered in the probabilistic sensitivity analysis including all of the patient subgroups evaluated in the model. This is a scatter plot in which each point represents a probabilistic analysis. The subgroups can be viewed together in different colors. The diagonal lines represent the costeffectiveness thresholds according to the definitions of the World Health Organization:(17) treatments that cost less than the value of one GDP per capita for each QALY gained are very cost-effective and treatments that cost up to three times the value of the GDP per capita for each QALY gained are cost-effective.

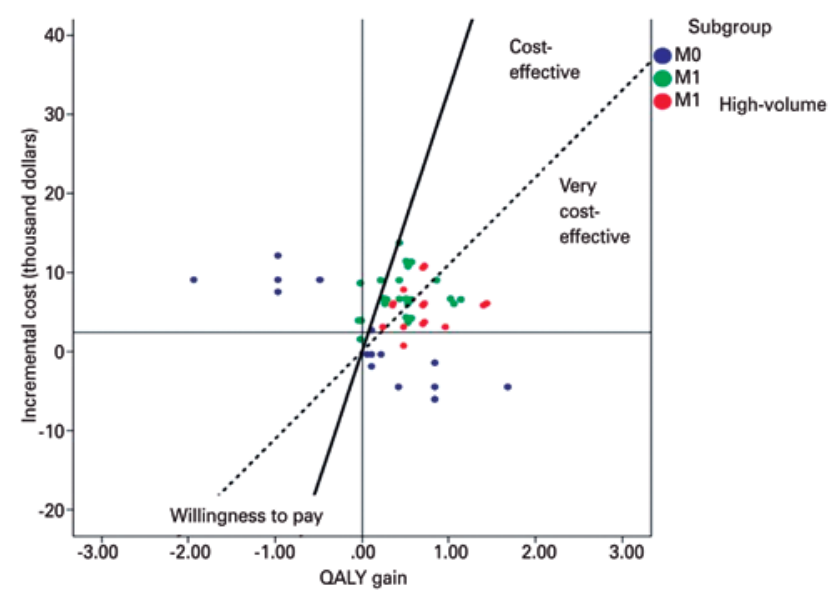

M0: non-metastatic; M1: all metastatic; QALY quality-adjusted life-year.

Figure 3. Cost-effectiveness of docetaxel plus androgen deprivation therapy for prostate cancer

\section{DISCUSSION}

The addition of chemotherapy to androgen deprivation therapy (ADT) represented a paradigm shift when initially used for the treatment of prostate cancer. ${ }^{(6-8,11,18)}$ However, there was a more pronounced practice change for patients with high-volume or more aggressive metastatic disease as a result of the differences between the GETUG-AFU 15 and CHAARTED studies. ${ }^{(6,18)}$ The first study included about $30 \%$ of patients with high-volume disease and did not find a benefit, while the second study included $70 \%$ of individuals with high-volume disease and found a statistically significant benefit. ${ }^{(6,11)}$

The aging population in Brazil may lead to an increase in the number of individuals with cancer. ${ }^{(19)}$ Furthermore, the development of potentially expensive new technologies may lead to a significant increase in cancer treatment costs. ${ }^{(20)}$ In Brazil, the expenses in cancer drug acquisition has increased almost three times in the past ten years. ${ }^{(21)}$ Approximately U\$ 2.5 billion are spent each year on cancer drugs. ${ }^{(21)}$ Therefore, it is fundamental to evaluate the cost-effectiveness of the treatments.

Although the relevance of cost-effectiveness analyses are increasing, there is still great difficulty in defining an accepted ICER threshold. ${ }^{(20)}$ In an attempt to facilitate the interpretation of these data, the World Health Organization suggests that for a treatment to be costeffective it must cost up to three times the value of GDP per capita per QALY gained, and for a treatment to be very cost-effective it must cost less than the GDP per capita. ${ }^{(17)}$ In the US the cost-effectiveness threshold is US\$ 50,000 per QALY gained. This value is based on the costs required for hemodialysis treatment for patients with chronic renal failure. However, recent studies suggest this figure should be increased to US $\$ 100,000$ or US\$150,000. ${ }^{(22)}$ In the United Kingdom, the most commonly used threshold is $£ 30,000.00$ per QALY.

Considering these cost-effectiveness thresholds, we consider that the findings in this study are robust since they fall within the cost-effectiveness thresholds in the majority of the probabilistic sensitivity analysis performed. The most cost-effective treatment group was patients with high volume metastatic disease (up to six times more cost-effective compared to patients with non-metastatic neoplasms).

In the other hand, a Chinese study assessed the same question in China. The addition of docetaxel was not cost-effective for all patients with metastatic disease, although this treatment may be cost-effective for a minority of sensitivity analysis among patients with disease of high-volume. The incremental QALY found by the Chinese authors and by our group are quite similar. ${ }^{(23)}$ This endorses the replicability and robustness of our findings. Moreover, our study was the only that assessed the cost-effectiveness of the addition of docetaxel to ADT for non-metastatic disease. 
Although the thresholds proposed by World Health Organization facilitate the interpretation of costeffectiveness studies and the definition of the implementation of new technologies, these values consider only economic aspects of the population. Epidemiological, cultural, psychological, and spiritual aspects are not taken into account in this evaluation. For example, new treatment for a rare disease with limited therapeutic options may accept a higher costeffectiveness threshold than a new treatment for a prevalent disease with good therapeutic options.

In addition, the discussion about the monetary value that should be invested in an individual's life is very complex in Brazilian society. Furthermore, it is very difficult to standardize cost-effectiveness thresholds for individuals in different social strata.

There are fundamental questions regarding the interpretation of these findings that have not been fully addressed. One of the major limitations of this study was that the estimate of the quality of life based on data from the literature may be different from the Brazilian values and lead to possible changes in the findings. Since there are no Brazilian data to be used, it is extremely important to develop other quality of life studies in Brazil.

In our study, we included clinical data from randomized studies within populations outside of Brazil, which may differ from studies conducted in a Brazilian population. Therefore, the need for clinical studies in Brazil is required to confirm that data from international clinical studies are relevant.

\section{CONCLUSION}

The addition of chemotherapy to the hormone treatment of prostate cancer is a cost-effective measure for patients with extensive (high-volume) metastatic disease. However, studies regarding the clinical effectiveness and quality of life are necessary to confirm these findings in Brazil.

\section{REFERENCES}

1. Ferlay J, Soerjomataram I, Dikshit R, Eser S, Mathers C, Rebelo M, et al. Cancer incidence and mortality worldwide: sources, methods and major patterns in GLOBOCAN 2012. Int J Cancer. 2015;136(5):E359-86.

2. Instituto Nacional de Cancer José Alencar Gomes da Silva (INCA). Coordenação de Prevenção e Vigilância. Estimativa 2016: incidência de câncer no Brasil [Internet]. Rio de Janeiro: INCA; 2016 [citado 2017 Abr 24]. 124 p. Disponível em: http://www.inca.gov.br/estimativa/2016/estimativa-2016-v11.pdf

3. Siegel RL, Miller KD, Jemal A. Cancer statistics, 2016. CA Cancer J Clin. 2016;66(1):7-30.

4. Tourinho-Barbosa RR, Pompeo AC, Glina S. Prostate cancer in Brazil and Latin America: epidemiology and screening. Int Braz J Urol. 2016;42(6):1081-90. Review.
5. DeVita Jr. VT, Lawrence TS, Rosenberg SA. Cancer: principles and practice of oncology. 10th ed. EUA: LWW; 2014.

6. Gravis G, Fizazi K, Joly F, Oudard S, Priou F, Esterni B, et al. Androgendeprivation therapy alone or with docetaxel in non-castrate metastatic prostate cancer (GETUG-AFU 15): a randomised, open-label, phase 3 trial. Lancet Oncol. 2013;14(2):149-58.

7. James ND, Sydes MR, Clarke NW, Mason MD, Dearnaley DP, Spears MR, Ritchie AW, Parker CC, Russell JM, Attard G, de Bono J, Cross W, Jones RJ, Thalmann G, Amos C, Matheson D, Millman R, Alzouebi M, Beesley S, Birtle AJ, Brock S, Cathomas R, Chakraborti P, Chowdhury S, Cook A, Elliott T, Gale J, Gibbs S, Graham JD, Hetherington J, Hughes R, Laing R, McKinna F, McLaren DB, O'Sullivan JM, Parikh 0, Peedell C, Protheroe A, Robinson AJ, Srihari N, Srinivasan R, Staffurth J, Sundar S, Tolan S, Tsang D, Wagstaff J, Parmar MK; STAMPEDE investigators. Addition of docetaxel, zoledronic acid, or both to first-line long-term hormone therapy in prostate cancer (STAMPEDE): survival results from an adaptive, multiarm, multistage, platform randomised controlled trial. Lancet. 2016;387(10024):1163-77.

8. Fizazi K, Lesaunier F, Delva R, Gravis G, Rolland F, Priou F, et al. A phase III trial of docetaxel-estramustine in high-risk localised prostate cancer: a planned analysis of response, toxicity and quality of life in the GETUG 12 trial. Eur $\mathrm{J}$ Cancer. 2012:48(2):209-17.

9. Claxton K, Martin S, Soares M, Rice N, Spackman E, Hinde S, et al. Methods for the estimation of the National Institute for Health and Care Excellence cost-effectiveness threshold. Health Technol Assess. 2015;19(14):1-503, v-vi.

10. Bae $Y H$, Mullins $C D$. Do value thresholds for oncology drugs differ from nononcology drugs? J Manag Care Spec Pharm. 2014;20(11):1086-92.

11. Scott E. Chemohormonal therapy in metastatic hormone-sensitive prostate cancer. Sweeney CJ, Chen YH, Carducci M, Liu G, Jarrard DF, Eisenberger M, Wong YN, Hahn N, Kohli M, Cooney MM, Dreicer R, Vogelzang NJ, Picus J, Shevrin D, Hussain M, Garcia JA, DiPaola RS. Department of Medicine; Department of Biostatistics and Computational Biology; Dana-Farber Cancer Institute, Boston; Harvard Medical School, Boston; Johns Hopkins University, Baltimore; University of Wisconsin Carbone Cancer Center; School of Medicine and Public Health; Madison; Fox Chase Cancer Center, Temple University Health System, Philadelphia; Indiana University Melvin and Bren Simon Cancer Center, Indianapolis; Mayo Clinic, Rochester, MN; University Hospitals Case Medical Center, Seidman Cancer Center; Cleveland Clinic Taussig Cancer Institute; Both in Cleveland; University of Virginia Cancer Center, Charlottesville; Comprehensive Cancer Centers of Nevada, Las Vegas; Siteman Cancer Center, Washington University School of Medicine, St. Louis; NorthShore University Health System, Evanston, IL; University of Michigan Comprehensive Cancer Center, Ann Arbor; Rutgers Cancer Institute of New Jersey, New Brunswick. N Engl J Med. 2015;373(8):737-46.

12. Konski A. Radiotherapy is a cost-effective palliative treatment for patients with bone metastasis from prostate cancer. Int J Radiat Oncol Biol Phys. 2004;60(5):1373-8.

13. Doyle S, Lloyd A, Walker M. Health state utility scores in advanced non-small cell lung cancer. Lung Cancer. 2008;62(3):374-80.

14. Nafees B, Stafford M, Gavriel S, Bhalla S, Watkins J. Health state utilities for non small cell lung cancer. Health Qual Life Outcomes. 2008;6:84.

15. Elsada A, Pearce F, George E, Adler A. NICE guidance on enzalutamide for metastatic hormone-relapsed prostate cancer. Lancet Oncol. 2014;15(10): 1058-9.

16. Kairos. Revista de Ciência e Tecnologia para sua Farmácia. Preços dos medicamentos constantemente atualizados [Internet]. Brasil: Kairos; 2016 [citado 2017 Abr 25]. Disponível em: http://brasil.kairosweb.com/

17. Marseille E, Larson B, Kazi DS, Kahn JG, Rosen S. Thresholds for the costeffectiveness of interventions: alternative approaches. Bull World Health Organ. 2015;93(2):118-24.

18. Vale CL, Burdett S, Rydzewska LHM, Albiges L, Clarke NW, Fisher D, Fizazi K, Gravis G, James ND, Mason MD, Parmar MKB, Sweeney CJ, Sydes MR, Tombal B, Tierney JF; STOpCaP Steering Group. Addition of docetaxel or bisphosphonates to standard of care in men with localised or metastatic, 
hormone-sensitive prostate cancer: a systematic review and meta-analyses of aggregate data. Lancet Oncol. 2016;17(2):243-56. Review. Erratum in: Lancet Oncol. 2016;17(2):e46.

19. Who Health Organization (WHO). International Agency for Research on Cancer (IARC). GLOBOCAN 2012: estimated Cancer Incidence, Mortality and Prevalence Worldwide in 2012. Population Fact Sheets. Estimated agestandardised incidence and mortality rates: men [Internet]. France: IARC; 2017 [cited 2016 Jul 27]. Available from: http://globocan.iarc.fr/Pages/fact_ sheets_population.aspx

20. Saltz LB. Perspectives on cost and value in cancer care. JAMA Oncol. 2016; 2(1):19-21.
21. Brasil. Tribunal de Contas da União (TCU). Relatório de Auditoria Operacional. Política Nacional de Atenção Oncológica. [Jorge J, Ministro Relator]. Brasília: TCU; 2011.

22. Neumann PJ, Cohen JT, Weinstein MC. Updating cost-effectiveness--the curious resilience of the $\$ 50,000$-per-QALY threshold. N Engl J Med. 2014; 371(9):796-7.

23. Zheng HR, Wen F, Wu YF, Wheeler JR, Li O. Cost-effectiveness analysis of additional docetaxel for metastatic hormone-sensitive prostate cancer treated with androgen-deprivation therapy from a Chinese perspective. Eur J Cancer Care (Engl). 2016 May 3. [Epub ahead of print]. 